\title{
Properties Evaluation of Concrete Using Local Used Bricks as Coarse Aggregate
}

\author{
Riaz Bhanbhro1,2, Irfanullah Memon², Aziz Ansari', Ahsan Shah"2, Bashir Ahmed Memon² \\ ${ }^{1}$ Luleå University of Technology, Luleå, Sweden \\ ${ }^{2}$ Quaid-e-Awam University, Nawabshah, Pakistan \\ Email: riaz.bhanbhro@ltu.se, irfanullahmemon@yahoo.com, bashir m@hotmail.com
}

Received 3 February 2014; revised 3 March 2014; accepted 10 March 2014

Copyright @ 2014 by authors and Scientific Research Publishing Inc.

This work is licensed under the Creative Commons Attribution International License (CC BY).

http://creativecommons.org/licenses/by/4.0/

(c) ()

\begin{abstract}
With time concrete/reinforced concrete has become the popular material for construction, modern industry utilizes this material a lot and has produced various beautiful, eye catching and amazing structures. Due to modern requirements for living and developed construction industries, the old buildings (usually constructed with brick masonry) are demolished and are replaced with new modern buildings. Demolition of buildings results in waste materials which can create waste related problems and environmental issues. By using recycled aggregates, weight of concrete can also be reduced, which can also solve problems related to self-weight of concrete. In this paper attempt has been made to use local used bricks from vicinity of Nawabshah, Pakistan, as coarse aggregate. Concrete cubes made with local recycled bricks are cast and tested for overall weight of concrete, moisture content, dynamic modulus of elasticity and compressive strength (nondestructive and destructive methods). The results showed that concrete derived from recycled aggregates attained lower strength than regular concrete. More detailed and elaborated work is recommended with different mix ratios and different proportions of recycled aggregates for better conclusion.
\end{abstract}

\section{Keywords}

Lightweight Concrete; Recycled Aggregates; Used Local Bricks

\section{Introduction}

Due to growing needs for living and development of construction industries and, the old or expired buildings, constructed with brick masonry, are usually demolished in Pakistan in order to construct new buildings or plazas. Demolishment of old buildings produces waste material (brick blasts) which needs to be utilized in new 
construction. These waste materials usually dumped illegally or as landfill material, can be reused to reduce environmental issues [1] and also can save some pennies.

These demolished materials, which are usually brick blasts, can be used in making new concretes; this also makes possible to eradicate waste related problems [2]. Furthermore reusing the brick blasts as coarse aggregate in concrete can significantly reduce the weight of concretes as well. Concrete is utilized to a great extent in modern construction industry however; self-weight of concrete is itself a problem especially towards construction of sky scraper construction. In this regard various materials are being used as lightweight aggregates in concrete including recycled aggregates, bricks, glass, steel nails, industry waste and fly ash focusing on without compromising the strength of concrete.

The object of this study was to investigate the use of the recycled bricks as light weight coarse aggregate in concrete and to reduce waste related issues as well in the vicinity of city Nawabshah, Pakistan. Used bricks collected from old demolished buildings from Nawabshah city are used as coarse aggregate. In preparation of concrete cubes, coarse aggregates were replaced with used bricks, whereas for fine aggregates sand was used. Ordinary Portland Cement (OPC) was used as binding material. After concrete mix design, cubes were prepared and cured for 7, 14 and 28 days. At the end of each curing period the cubes were then tested for moisture content, dynamic modulus of elasticity and compressive strength (by hydraulic loads nondestructive testing method). In order to compare the results, the cubes with regular crushed stone aggregates were also prepared and cured for similar time (i.e. 7, 14 and 28 days) to evaluate the properties of concrete used with recycled aggregates.

\section{Materials and Test Methods}

\subsection{Concrete Mix}

Concrete cubes of size $(203 \mathrm{~mm} \times 203 \mathrm{~mm} \times 203 \mathrm{~mm})$ were casted for this study. Concrete mix made from regular dense aggregates was done by weight and that of recycled aggregates was also done by weight except the aggregate taken by volume of that used in concrete with dense aggregate. The recycled aggregate derived from recycled bricks possessed grain size in range of $6 \mathrm{~mm}$ to $20 \mathrm{~mm}$. The specimens (cubes) were made in three batches, which differ in curing, i.e. seven days, fourteen days and twenty-eight days. All concrete mixtures had the same details i.e. the water/cement ratio of 0.5; the type of cement used was Ordinary Portland Cement (OPC) and mix ratio 1:2:4 i.e. one part of cement, two parts of fine aggregates and four parts of coarse aggregates. Because of higher absorption capacity of concrete used with recycled bricks [3], the brick aggregates were cured for twenty four hours before mixing them with water and cement to get concrete mix.

Different series of concrete cubes were prepared i.e. mainly in three batches. Concrete made with recycled aggregates is here called as Series A, B and C whereas concrete made with regular dense aggregates is denoted as Series A1, B1, and C1. Series A contained eight cubes, each of volume $203 \mathrm{~mm}^{3}$ and cured for seven days. Series B contained eight cubes and each of volume $203 \mathrm{~mm}^{3}$ cured for 14 days. And series C contained eight cubes each of $203 \mathrm{~mm}^{3}$ and were cured for 28 days. Similarly the Series A1, B1 and C1 contained same number of cubes, volume and curing period as Series A, B and C respectively. The only difference was replacement of recycled bricks aggregates with natural dense aggregates.

\subsection{Nondestructive Compressive Strength}

Nondestructive compressive Strength was determined by Rebound Hammer (Figure 1—right). Rebound hammer readings were taken at all edges of cube including center of cube. The test depends upon on rebound of elastic mass against hardness of surface. The average value of all rebound readings on one cube i.e. (all edges and center) is then calculated.

Calculation was done for all cubes of 7, 14 and 28 days curing. The concrete made with recycled brick aggregates showed slightly lower values of rebound as compared to concrete made with natural aggregates.

\subsection{Dynamic Modulus of Elasticity}

The properties of aggregates and cement paste have influence on overall dynamic modulus of elasticity concrete [4]. The modulus of elasticity of aggregates and cement are different and this has overall impact on elasticity of concrete [4]. The Digital Young's Modulus meter (Figure 2-right) was used for finding resonant frequency passed from specimens $(203 \mathrm{~mm} \times 203 \mathrm{~mm} \times 203 \mathrm{~mm}$ ) for finding the dynamic modulus of elasticity. In this 


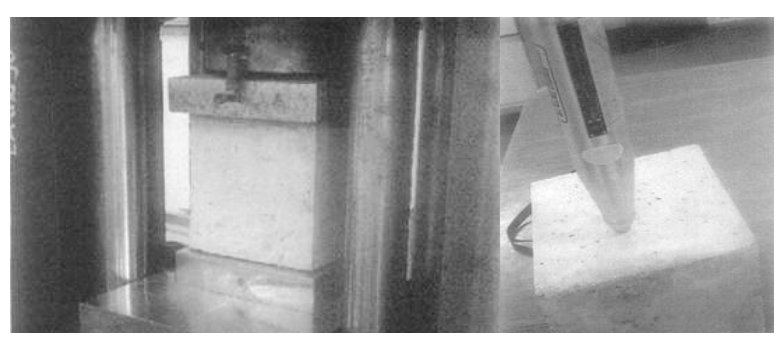

Figure 1. Specimen placed for compression test (left), rebound Hammer during test (right).

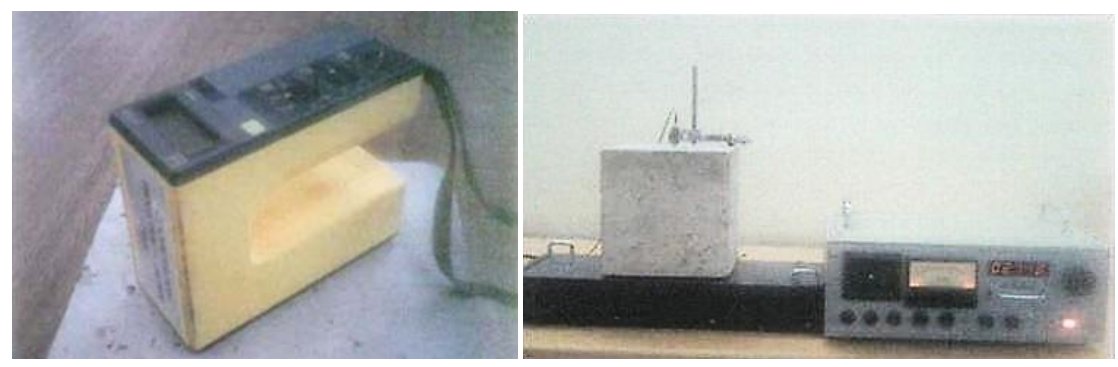

Figure 2. Moisture meter (left), cube placed on dynamic modulus meter (right).

research the resonant frequencies were measures in vertical direction, and equation for calculating dynamic modulus of elasticity is presented as Equation (1):

$$
\text { Dynamic } E=C \times W \times f^{2}\left(\mathrm{~kg} / \mathrm{cm}^{2}\right)
$$

where $C$ is a constant value for apparatus $408 \times 10^{-5} \times(L / A), f$ is Primary resonance vibration frequency of the vertical vibration, $L$ is Specimen's Length $(\mathrm{cm}), A$ is Specimen's cross-sectional Area $\left(\mathrm{cm}^{2}\right)$ and $W$ is Specimen's weight $(\mathrm{kg})$.

\subsection{Compressive Strength}

In compressive strength tests, the specimens were placed in hydraulically operated compression machine in a way that plates of machine were in contact with specimens cast faces (Figure 1-left). The loads were then applied gradually with rate of $15 \mathrm{MPa}$ per minute till failure of the cube specimens. As the bricks aggregates are very angular in shape, they exhibited good bond with cement which resulted breaking right through maintaining the bond with cement paste [5].

\subsection{Moisture Content}

Digital type moisture meter (Figure 2-left) was used for determination of moisture content in specimens. This device can measure the moisture content within the specimen without damaging its surface and operates on principle of electronic capacitance. After taking cubes from curing tank they were cleaned and placed on piece of cloth and then moisture readings were taken. Average reading from specimens was based upon several readings from different sides of cubes being tested.

\section{Results and Discussion}

The average bulk density of concrete made with recycled aggregates was found to be $1912 \mathrm{~kg} / \mathrm{m}^{3}$ and same for the regular concrete was found as $2280 \mathrm{~kg} / \mathrm{m}^{3}$. The bulk density of recycled aggregate concrete was calculated to be $16 \%$ less as compared to regular concrete. The summary of moisture content results is presented in Table 1. The moisture content for series A was in range of $4.2 \%$ to $5.8 \%$, which is $35 \%$ to $45 \%$ higher than series A1. This can be mainly because of higher water absorption capacity of recycled aggregates [3]. The average moisture content for series B was found to be $4.7 \%$ which is $23.4 \%$ higher than series B1. The average moisture content for Series C and C1 was close to $4.5 \%$. 
Table 1. Summary of measurement of moisture content.

\begin{tabular}{|c|c|c|c|c|c|c|c|c|c|c|}
\hline \multirow{2}{*}{ Series } & \multirow{2}{*}{$\begin{array}{l}\text { Moisture } \\
\text { Content }\end{array}$} & \multicolumn{9}{|c|}{ Specimen } \\
\hline & & 1 & 2 & 3 & 4 & 5 & 6 & 7 & 8 & Avg. \\
\hline A & $\%$ & 4.2 & 5.2 & 5.8 & 4.9 & 4.5 & 4.7 & 5.4 & 4.6 & 4.9 \\
\hline B & $\%$ & 4.4 & 4.48 & 4.13 & 4.63 & 4.6 & 4.15 & 4.6 & 4.28 & 4.7 \\
\hline $\mathrm{C}$ & $\%$ & 5.15 & 4.75 & 4.73 & 5.5 & 4.65 & 4.45 & 4.1 & 4.58 & 4.4 \\
\hline A1 & $\%$ & 3.14 & 2.82 & 2.92 & 2.72 & 3.06 & 2.76 & 2.94 & 2.78 & 2.9 \\
\hline B1 & $\%$ & 3.04 & 3.34 & 3.6 & 3.88 & 3.96 & 3.9 & 3.62 & 3.92 & 3.6 \\
\hline C1 & $\%$ & 4.8 & 5.06 & 4.52 & 4.52 & 4.6 & 4.7 & 4.02 & 4.54 & 4.5 \\
\hline
\end{tabular}

It was observed that concrete made with regular aggregates gradually attained higher moisture content as time of curing was increasing, however, the concrete made with recycled aggregates showed less effect on moisture content with rate of curing.

Both concretes did not perform well in terms of strength. This might be because of cement type, water cement ratio, preparation methods etc. used. The dynamic modulus of elasticity calculated from Equation (1) for concrete was found to be in range of $19821 \mathrm{~kg} / \mathrm{cm}^{2}$ to $10929 \mathrm{~kg} / \mathrm{cm}^{2}$ which was $29 \%$ higher than that measured for concrete made with recycled aggregates. Lower dynamic modulus of elasticity might be because of measured technique of passage through which frequency was passed, contained more (or less) coarser particles.

The average compressive strength (Figure 3) calculated by rebound hammer (nondestructive method) for the Series A, B and C was found to be $17.1 \mathrm{~N} / \mathrm{mm}^{2}, 19.2 \mathrm{~N} / \mathrm{mm}^{2}$ and $22.37 \mathrm{~N} / \mathrm{mm}^{2}$ respectively, which is $13.6 \%$, $27 \%$ and 27\% less than the regular concrete (Figure 4) of Series A1, B1 and C1 respectively. The compressive strength determined by destructive method for the concrete (Figure 5) of Series A, B, and C was determined as $21.2 \mathrm{~N} / \mathrm{mm}^{2}, 21.6 \mathrm{~N} / \mathrm{mm}^{2}$, and $21.6 \mathrm{~N} / \mathrm{mm}^{2}$ respectively. This strength was $23.2 \%, 34 \%$ and $37 \%$ less as compared to regular concrete (Figure 6) of Series A1, B1 and C1 respectively. The compressive strength of concrete with recycled aggregates obtained by nondestructive method (Rebound Hammer) was about $3 \%$ more than that of the destructive method for same concrete. Similarly, the nondestructive compressive strength of concrete made with regular aggregates was about $11 \%$ less than the destructive method for same samples.

\section{Conclusion}

This study evaluated the basic properties of concrete derived from local recycled bricks from Nawabshah city, Pakistan. Results presented in this paper show that, by using recycled aggregates as coarse aggregates in concrete, the overall density can be reduced up to $16 \%$ as compared to regular concrete. Concrete prepared with recycled aggregates showed similar behavior in terms of moisture content against curing age of concrete i.e. seven, fourteen and twenty-eight days, whereas regular concrete gained moisture slowly with age of curing of concrete. Compressive strength of concrete made with recycled aggregates was found to be $23.2 \%$, $34 \%$ and $37 \%$ less as compared to concrete made with regular aggregates for 7, 14 and 28 days of curing period respectively. Compressive strength determined by rebound hammer was found to be in agreement (3\% more) with compressive strength found by crushing for concrete made with recycled aggregates.

\section{Recommendations}

The aim of this experimental work was the investigation of possibilities of utilization of local waste/recycled bricks, produced in vicinity of Nawabshah, as coarse aggregates for concrete. This investigation is preliminary and future work will address extensive investigations in order to obtain final conclusions and possibilities of application of recycled bricks as coarse aggregates for concrete. Although results of this study are not as were expected. However more elaborated work is required with different mix ratios and different percentages of used bricks for better conclusions. 


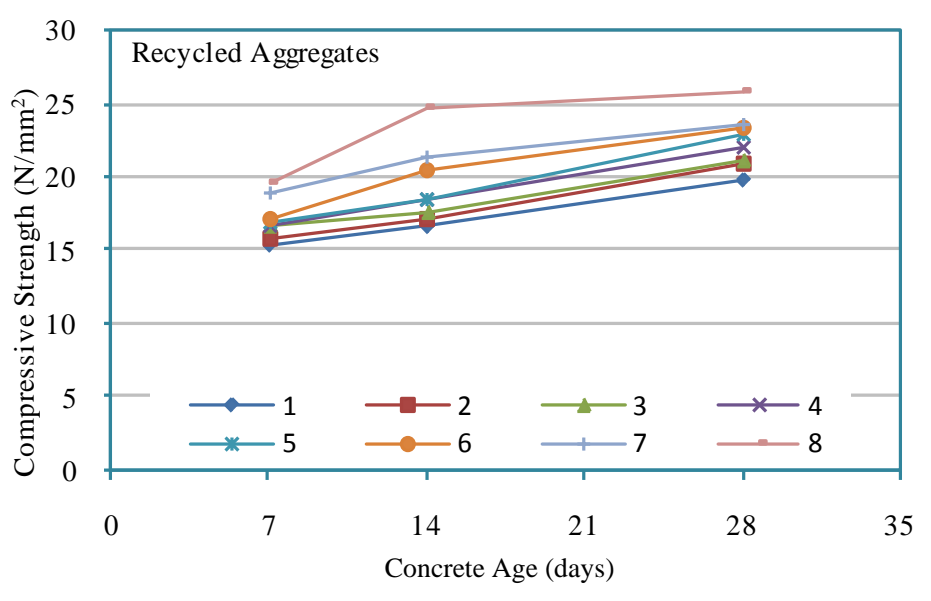

Figure 3. Compressive strength (rebound hammer) of series A, B and C.

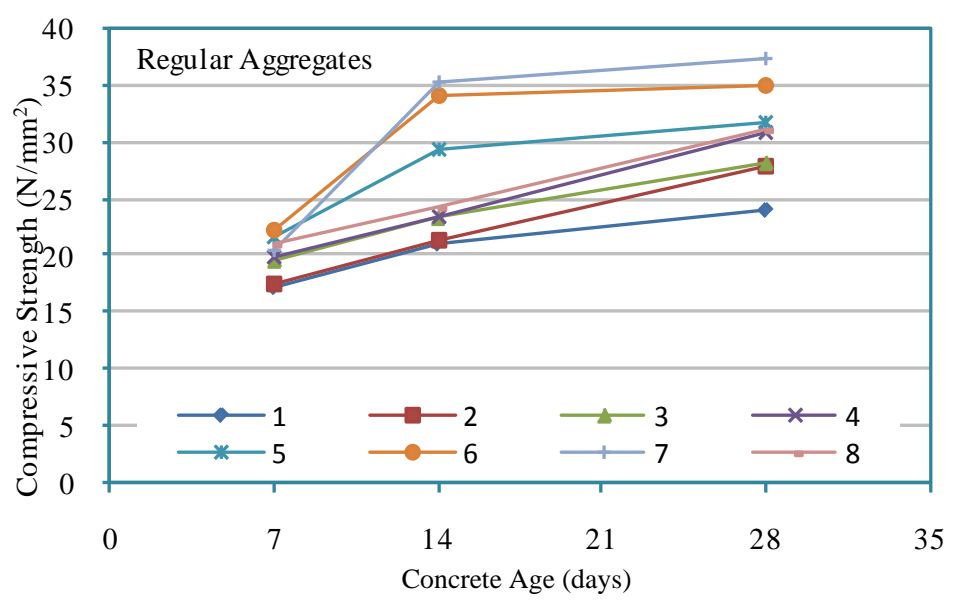

Figure 4. Compressive strength (rebound hammer) of series A1, B1 and C1.

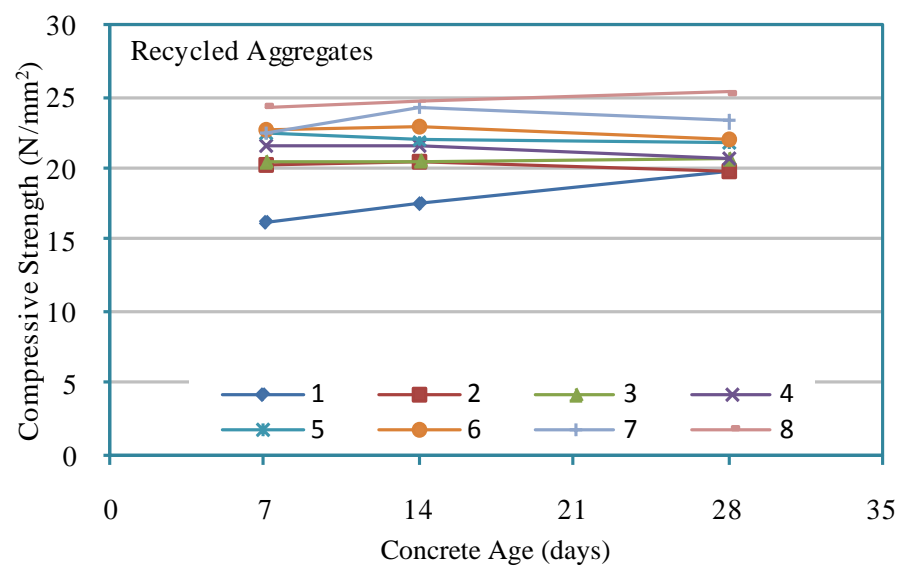

Figure 5. Compressive strength of series A, B and C.

\section{Acknowledgements}

The authors would like to thank Quaid-e-Awam University of Engineering, Science and Technology, Nawabshah, Pakistan as most of Laboratory work was performed there. The work presented here was conducted as part of research during undergraduate studies of first four authors (03CE12, 03CE70, 03CE01, 03CE33). Support 


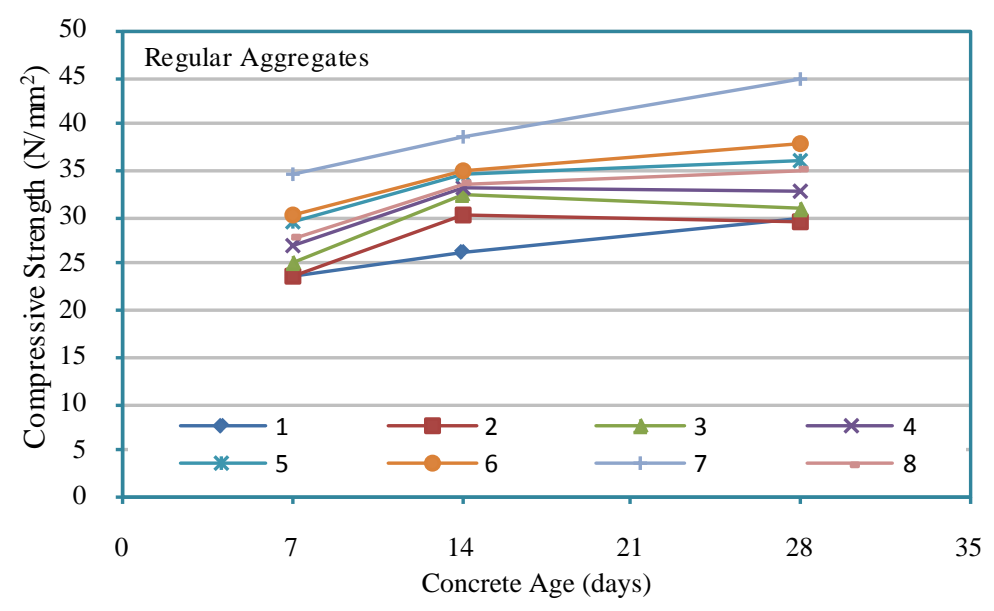

Figure 6. Compressive strength of series A1, B1 and C1.

from Luleå University of Technology, Sweden is also highly acknowledged for help in different aspects.

\section{References}

[1] Batayneh, M., Marie, I. and Asi, I. (2007) Use of Selected Waste Materials in Concrete Mixes. Waste Management, 27, 1870-1876. http://dx.doi.org/10.1016/j.wasman.2006.07.026

[2] Kesegic, I., Netinger, I. and Bjegovic, D. (2008) Recycled Clay Brick as an Aggregate for Concrete: Overview. Technical Gazette, 15, 35-40.

[3] Debieb, F. and Kenai, S. (2008) The Use of Coarse and Crushed Bricks as Aggregate in Concrete. Construction and Building Materials, 22, 886-893. http://dx.doi.org/10.1016/j.conbuildmat.2006.12.013

[4] Raman, S.N., Safiuddin, M. and Zain, M.F.M. (2007) Non-Destructive Evaluation of Flowing Concretes Incorporating Quarry Waste. Asian Journal of Civil Engineering (Building and Housing), 8, 597-614.

[5] Khalaf, F. (2006) Using Crushed Clay Brick as Coarse Aggregate in Concrete. Journal of Materials in Civil Engineering, 18, 518. http://dx.doi.org/10.1061/(ASCE)0899-1561(2006)18:4(518) 